Rapid Reviews COVID-19

\title{
Reviews: "Contact Tracing Efficiency, Transmission Heterogeneity, and Accelerating COVID-19 Epidemics"
}

\section{Laura White ${ }^{1}$}

${ }^{1}$ Boston University

Published on: Mar 03, 2022

License: Creative Commons Attribution 4.0 International License (CC-BY 4.0). 
To read the original manuscript, click the link above.

\section{Reviewer 1 (Laura W...) |}

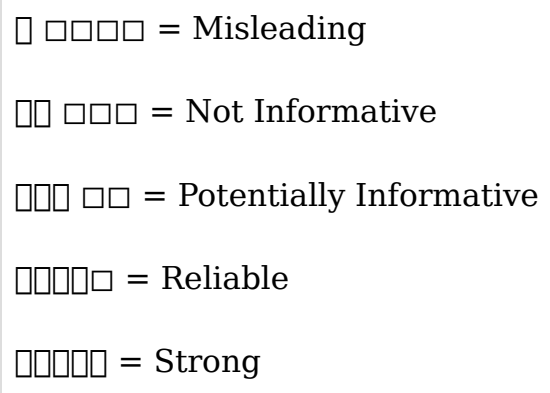

To read the reviews, click the links below. 